\title{
Can the Dental Practitioner help in the Management of Type 1 Diabetes Mellitus (DM-1)?
}

\author{
Hadeel NA Al Jurayyan*1, Renad EA AbdelNabi² and Nasir AM Al Jurayyan ${ }^{3}$ \\ ${ }^{1}$ Dental student, College of Dentistry, Princess Nourah Bint Abdulrahman University, Saudi Arabia \\ ${ }^{2}$ Pediatric Endocrinology, King Saud University, Saudi Arabia
}

${ }^{3}$ Professor and Consultant Pediatric Endocrinologist and diabetologist, King Saud University, Saudi Arabia

Received: 濫: November 12, 2018; Published: 監: November 26, 2018

*Corresponding author: Hadeel N Al Jurayyan, Department of Dentistry, Princess Nourah Bint Abdulrahman University, Saudi Arabia

\begin{abstract}
Diabetes Mellitus Type 1 (DM-1) is a complex endocrine disorder characterized by elevated levels of glucose in the blood. This elevation is the result of insulin deficiency, leading to a variety of metabolic abnormalities involving carbohydrate, fat and protein. A number of oral disorders have been associated with Diabetes Mellitus, such as gingivitis and periodontitis. In addition, dental caries, salivary dysfunctions, oral mucosal diseases, oral infections such candidiasis and other neurosensory disorders. In this report, we review the association of oral health and Diabetes Mellitus Type 1 (DM-1) and highlight the role of the dental practitioner in the management.
\end{abstract}

Keywords: Diabetes Mellitus Type 1; Oral Hygiene; Periodontitis; Dental Caries; Oral Mucosal Disorder; Dentist

\section{Opinion}

Diabetes Mellitus, is a complex metabolic disorder characterized by disturbed metabolism of carbohydrate, fat and protein, resulting from a deficiency of insulin secretion or its action. It is the most common endocrine/metabolic disorder in childhood and adolescence. The application of molecular biological tools continue to provide remarkable insights into the etiology, the pathophysiology and the genetics of the different forms of Diabetes Mellitus that result from deficient secretion of insulin or its action at the cellular level. Morbidity and mortality stem from metabolic derangements and from the long-term complications that affect small and large vessels resulting inn retinopathy, nephropathy, neuropathy, ischemic heart disease, arterial obstructions and other macrovascular disease and new tissue healing. The acute clinical manifestations can be fully understood in the context of current knowledge of the secretion and action of insulin.

Genetic and other etiologic consideration implicate autoimmune mechanisms in the evolution of the most common form of childhood diabetes, known as Type 1 Diabetes Mellitus (DM-1). There is a consensus that the long-term complications are related to the degree and duration of metabolic disturbance. These considerations form the basis of therapeutic approaches to the disease that include newer pharmacological formulations of insulin, delivery by traditional and more physiological means and evolving methods to monitor blood glucose so as to maintain it within desired limits [1,2].

\section{Oral Manifestations of Diabetes Mellitus}

A number of oral disorders have been associated with Diabetes Mellitus, some of which are listed below [3-10]:

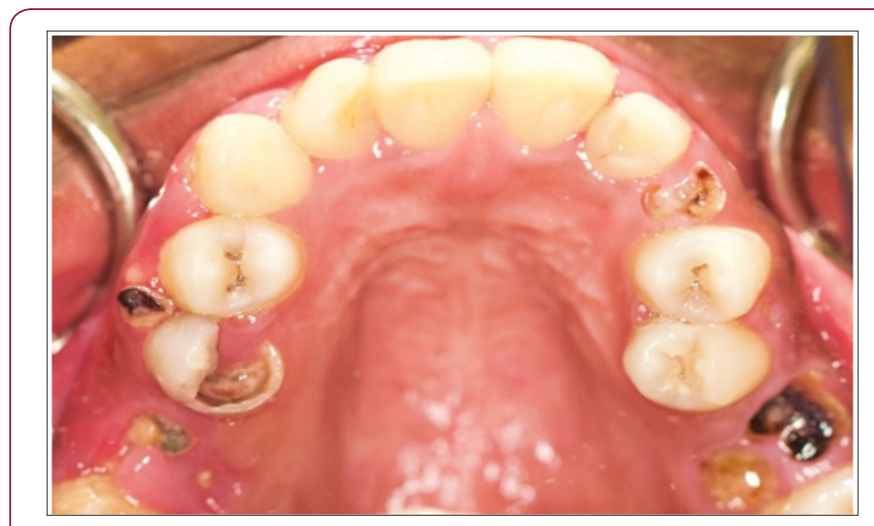

Figure 1: Dental caries in a patient with poorly controlled diabetes mellitus type 1 (DM-1).

Dental Caries: The relationship with Diabetes Mellitus is complex and could be related to the type and nature of the diet 
given and also diminished salivary flow (Figure 1). However, the literatures present no consistent pattern regarding the relationship of dental caries and diabetes.

Salivary dysfunction: Dry mouth or xerostomia has been reported in patients with Diabetes Mellitus [5,10].

Oral Mucosal Diseases, Gingivitis and Periodontitis: A number of oral mucosal lesions, such as candidiasis and aphthous stomatitis have been reported in Diabetes Mellitus. This is often due to poor salivary flow [5,10-12]. Oral candidiasis has been a more consistent finding in patients with diabetes mellitus. Figure 2 periodontal disease is a recognized and well documented complication of diabetes mellitus. Figure 3 data suggest that periodontal disease may increase the risk of experiences poor diabetic control [4].

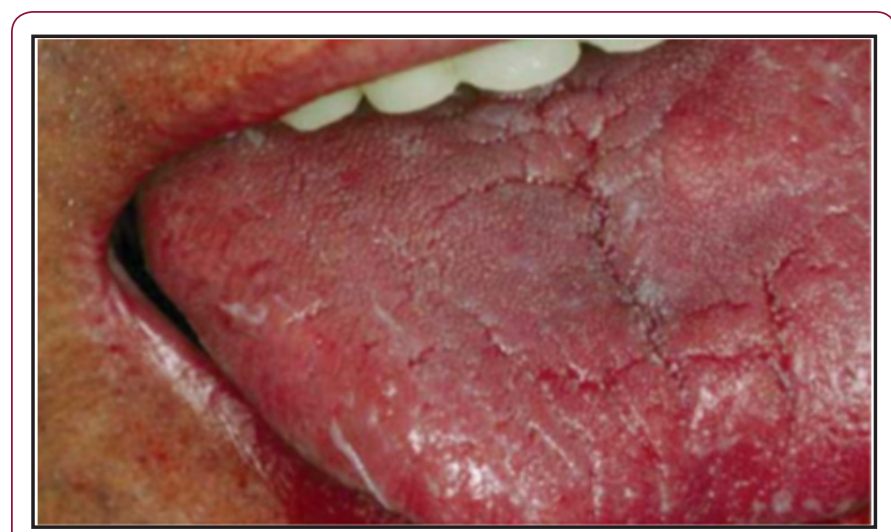

Figure 2: Oral candidiasis in a patient with poorly controlled diabetes mellitus.

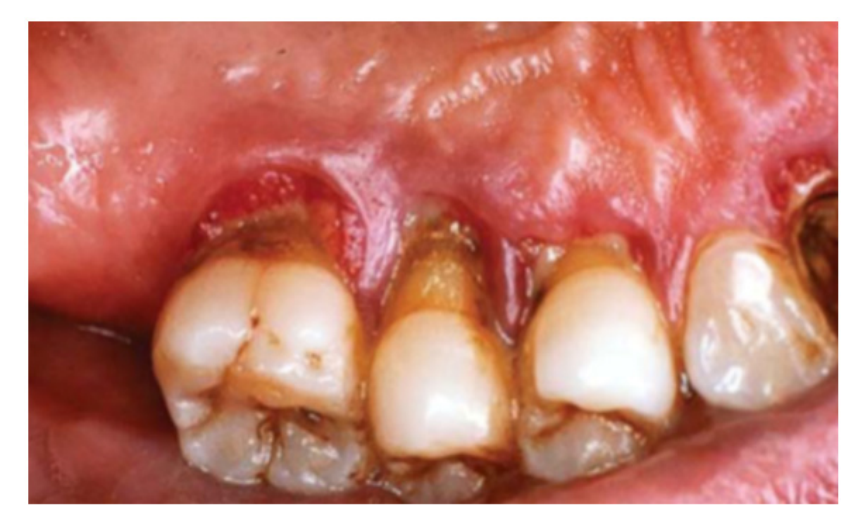

Figure 3: periodontal disease in a poorly controlled diabetic patient.

Taste and Other Neurosensory Disorders: It is a complex symptom and might compromise the patient's ability to perform mouth hygiene $[3,10]$. The current evidence on knowledge, attitude and practice of patients with Diabetes Mellitus in relation to oral health care is limited. Some studies have demonstrated a positive influence on the metabolic control of diabetes and that the higher glucose content in oral fluids contribute to bacterial proliferation, increasing the formation of dental plaque and leading to periodontal disease. Diabetics with severe disease have a higher risk for complications [13-23]. Despite worldwide recognition of the dangers of Diabetes Mellitus, diabetic patients' awareness and attitude towards their heightened risk for oral diseases has not been fully addressed. Oral hygiene behavior and seeking oral health care depend on a number of factors.

Lack of knowledge about dental health and poor compliance with dental hygiene are amongst the reasons for non-adherence to oral hygiene practices, economical constraints and lack of facilities and proper guidance. A cross sectional study was conducted by Ismail and Ali [24] including 612 diabetic patients visiting the primary health care centers in Abha city, Assir region, Saudi Arabia, which showed that more than half of the included patients (52.3\%) were not aware that diabetic patients are more prone to oral disease and only less than half of them (46.1\%) and (46.4\%) was deficient. Most diabetic patients know various medical complications of diabetes and the effect of Diabetes Mellitus. About the attitude and practice of diabetic patients towards oral health, the overall oral hygiene measures in diabetic patients were found to be good. This was similar to Kamran et al. [25] from Pakistan and contrasting to that of Rehan and Mansour [26].

\section{Role of the General Dentist}

Dentists' willingness to be involved in the primary health care activities, including managing diabetics should be addressed. Practicing dentists and co-workers can have a significant, positive effect on oral health of patients with Diabetes Mellitus [27-29].

\section{Conclusion}

Diabetes Mellitus is an important health care problem. It is a disease of which the general dentists (practitioners) and coworkers can have a significant, positive effect on the oral and general health of patients. Many aspects of dental care need to be improved to give the professional a chance to provide care for diabetic patients and, hence, improve the control. Therefore, a string liaison between the diabetic and dental teams is strongly recommended. Furthermore, full understanding and awareness of the pathophysiology, manifestations and management of different types of diabetes related orofacial infections by the endocrinologist and the dentist are essential to optimize control.

\section{Acknowledgment}

The authors would like to thank Mr. Abdulrahman N. A. Al Jurayyan and for his help in preparing this manuscript.

\section{References}

1. (2000) The expert committee on the diagnosis and classification of Diabetes Mellitus: Report of expert committee on the diagnosis and classification of Diabetes Mellitus. Diabetes Care (Surgery J) 23: 54.

2. (2011) American Diabetes Association: Diagnosis and classification of Diabetes Mellitus. Diabetes Care 34: 562-569.

3. Ship JA (2003) Diabetes and Oral Health. J Am Dent Assoc 134(1): 45-95.

4. Taylor GW, Borganakke WS (2008) Periodontal disease association with diabetes, glycemic control and complications. Oral Dis 14(3): 191-203.

5. Moore PA, Gyggenheimer J, Etzed KR, Weyant RJ, Orchard T (2001) Type 1 diabetes mellitus, xerostomia and salivary flow rates. Oral Surg Oral Med Oral Pathol Oral Radiol Endod 92(3): 281-291. 
6. Abdulrahman KA (2006) Diabetes Mellitus and its oral complications: A brief review. Pakistan Oral Dent J 26(1): 91-100.

7. Uneo M, Takouchi S, Oshiro A, Shinada K, Ohara S, et al. (2010) Association between Diabetes Mellitus and oral health status in Japanese adults. Int J Oral Sci 2(2): 82-29.

8. Radhika T, Kannan R (2012) Diabetes Mellitus and oral health. J Orofac Sci 4(1): 7-10.

9. Bell GW, Large DM, Barday SC (2000) Oral health care in Diabetes Mellitus. SADJ 55(3): 158-165.

10. Mauri-Obradors E, Estrugo Devesa A, Jane Salas E, Vifias M, Lopez Lopez J (2017) Oral manifestations of Diabetes Mellitus: A systematic review. Med Oral Patol Oral Cir Bucal 22(5): 586-594.

11. Guggenheimer J, Moore P, Rossie K (2000) Insulin dependent Diabetes Mellitus and oral soft tissue pathologies II; prevalence and characteristics of candida and candidal lesions. Oral Surg Oral Med Oral Pathol Oral Radiol Endod 89(5): 570-576.

12. Belazi M Velegraki A, Fleva A, Gidareteon I, Papanum L, Baka D, et al. (2005) Candidal overgrowth in diabetic patients: Potential predisposing factors. Mycoses 48(3): 192-196.

13. Kaur S, Kaur K, Rai S, Khajuria R (2015) Oral health management consideration in patients with Diabetes Mellitus. Arch Med Health Sci 3(1): 72-79.

14. Lamster IB, Lalla E, Borgnathke WS, Taylor GW (2008) The relationship between oral health and Diabetes Mellitus. JADA 139 (105): 19-24.

15. Poudel P, Griffiths R, Womg VW, Arora A, Flack JR, et al. (2018) Oral health knowledge attitudes and care practices of people with diabetes: A systematic review. BMC public Health 18(1): 577.

16. Alves C, Brandao M, Andion J, Menezes R (2009) Oral health knowledge and habits in children with type 1 Diabetes Mellitus. Braz Dent J 20(1): 70-73.

17. Lalla RV, Dambrosio JA (2001) Considerations for patients with Diabetes Mellitus. JADA 132(10): 1425-1432.

\section{ISSN: 2574-1241}

DOI: $10.26717 / B J S T R .2018 .11 .002080$

Hadeel NA Al Jurayyan. Biomed J Sci \& Tech Res

(C) (i) This work is licensed under Creative

This work is licensed under Creat
Commons Attribution 4.0 License

Submission Link: https://biomedres.us/submit-manuscript.php
18. Machado D, Coelho A, Paula Am Caramelo F, Carrilho F, Barros L, et al. (2017) Prevalence of dental caries in patients with type 1 Diabetes Mellitus treated with multiple insulin injections and that of individuals without diabetes. Acta Med Port 30(5): 402-408.

19. Peterson PE (2005) Priorities for research for oral health in the $21^{\text {st }}$ century - the approach of the WHO Global Oral health prpgramme. Community Dent Health 22(2): 71-74.

20. (2009) International Diabetes Federation Guidelines Task Force. Guideline - oral health for people with diabetes. Brussels: international Diabetes Federation.

21. Novotna M, Podzimek S, Broukal Z, Lencova E, Duskova J (2015) Periodontal diseases and dental caries in the children with type 1 Diabetes Mellitus. Mediators of Inflammation 2015: 3796268.

22. Bahammam M (2015) Periodontal health and diabetes awareness among Saudi diabetes patients. Patients Preference and Adherence 9: 225-233.

23. Tanwir F, Tariq A (2012) Effect of glycemic control on periodontal state. J Coll Physic Surg Pakistan 22(6): 371-374.

24. Ismaeil FM, Ali N (2013) Diabetic patients' knowledge, attitude and practice toward oral health. J Educat Practice 4(20): 19-27.

25. Kamran M, Ayyaz A, Munawer M (2007) Oral health knowledge, attitude and practice and source of information for diabetic patients in Lahore, Pakistan. Diabetic Care 30(12): 3046-3047.

26. Rehana Y, Mazoor AM (2011) Diabetic patients' level of awareness about oral health, knowledge, attitude and practice. Pakistan Oral Dent J 31: 2-8.

27. Yadav V, Mohanty V, Aswini YR (2017) Role of oral health professional as team care for Diabetes Mellitus. MAMC J Med Sci 3(2): 56-60.

28. Varon F, Mack-Shipman L (2000) The role of the dental professional in diabetes care. J Contemp Dent Pract 1(2): 1-27.

29. McKenna SJ (2006) Dental management of patients with diabetes. Dent Clin N Am 50(4): 591-606.

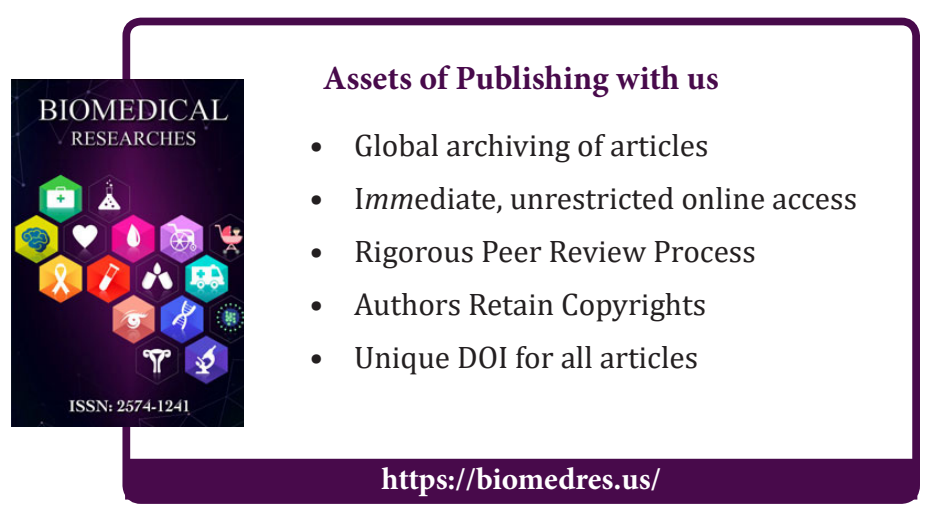

